\title{
BMJ Open Ongoing university studies and the risk of suicide: a register-based nationwide cohort study of 5 million young and middle-aged individuals in Sweden, 1993-2011
}

\author{
Christine Takami Lageborn, ${ }^{1}$ Rickard Ljung, ${ }^{2}$ Marjan Vaez, ${ }^{3}$ Marie Dahlin ${ }^{1}$
}

To cite: Lageborn CT, Ljung $\mathrm{R}$, Vaez $\mathrm{M}$, et al. Ongoing university studies and the risk of suicide: a register-based nationwide cohort study of 5 million young and middle-aged individuals in Sweden, 19932011. BMJ Open 2017;7: e014264. doi:10.1136/ bmjopen-2016-014264

- Prepublication history for this paper is available online. To view these files please visit the journal online (http://dx.doi.org/10.1136/ bmjopen-2016-014264).

Received 18 September 2016 Revised 29 January 2017 Accepted 9 February 2017

CrossMark

For numbered affiliations see end of article.

\section{Correspondence to} Dr Christine Takami Lageborn;

christine.takami@gmail.com

\section{ABSTRACT}

Objectives: To investigate the risk of suicide, unnatural death and all-cause death in university students compared with non-students, taking previous educational attainment into account.

Design: Open cohort study of all residents aged 18-39 and living in Sweden at any time between 1 January 1993 and 31 December 2011.

Setting: We linked data from national registers and calculated person-years during university studies for three time periods (1993-1999, 2000-2005 and 2006-2011). Time as non-student was calculated and categorised according to attained educational level. Incidence rate ratios (IRR) with $95 \%$ Cls were calculated with Poisson regression models, controlling for age and period.

Participants: The cohort consisted of 5039419 individuals, $51 \%$ men and $49 \%$ women.

Main outcome measures: Incidence of suicide (International Classification of Diseases (ICD)-9: E950-E959, ICD-10: X60-X84) or death with undetermined intent (ICD-9: E980-E989, ICD-10: Y10-Y34), unnatural death (ICD-9: E800-E999 and ICD-10: V01-Y99) and all-cause death.

Results: A total of 7316 deaths due to suicide were identified, of which 541 were registered among university students. The risk of suicide was twofold during ongoing university studies compared with when having attained university education, IRR $2.37(95 \% \mathrm{Cl}$ 2.07 to 2.72$)$ in men and IRR $2.15(95 \% \mathrm{Cl} 1.77$ to 2.61) in women.

Conclusions: Having ongoing university studies was associated with a higher risk of suicide compared with having attained university-level education. This finding highlights the importance of achieving a deeper understanding of suicidal behaviour during years at university. Further studies should assess risk factors for suicide and suicidal behaviour in university students.

\section{INTRODUCTION}

Suicide is one of the leading causes of death in young people globally, where men are up

\section{Strengths and limitations of this study}

- The first study on mortality among university students in a large nationwide cohort.

- The high quality and validity of Swedish national registers with complete nationwide coverage of exposure and a long follow-up time.

- The first study taking educational attainment into account when estimating suicide risk among university students.

- Generalisability of our results may be affected by differences in educational standards between countries.

- We have not examined the possible predictors for an increased suicide risk in university students.

to three times more likely than women to die by suicide. ${ }^{1}$ In several countries in the world an increasing proportion of young adults decide to pursue university studies. ${ }^{2}$ Almost $40 \%$ of young adults in high-income countries are expected to obtain a university degree during their lifetime. ${ }^{2}$ In Sweden, university students constitute a major part of the young adult population. The university period is accompanied by additional responsibilities and pressure to succeed, which may increase mental distress, depression or lead to excess alcohol use. ${ }^{4-7}$ In addition, university students have been found to experience low life satisfaction and to be more depressed than a non-student population of a similar age. ${ }^{4}{ }^{6}{ }^{8-11}$ As a result, some students may succumb to suicidal ideation and a greater risk of dying by suicide. ${ }^{12-15}$

Low educational attainment is associated with a higher risk of suicide as well as allcause death. ${ }^{16-19}$ Previous studies of suicide risk in university students have predominantly compared students with the general 
population, without taking education attainment into account, finding similar or lower suicide rates for university students when compared with age-matched populations. ${ }^{20-25}$ However, by not considering differences in educational attainment, they may have underestimated the risk of suicide in university students.

Our aim was to investigate the risk of suicide in university students compared with non-students, while taking educational attainment into account. We hypothesised that the risk of suicide would be higher during university studies compared with when having attained a university education.

\section{METHODS}

We included all Swedish residents aged 18-39 during 1993-2011 ( $\mathrm{N}=5039419)$. Newly turned 18-year olds entered into the open cohort each year. The cohort was followed until 31 December 2011. Subjects were censored at emigration, age 40 , death or end of follow-up. Information on eligible residents, country of birth and date of emigration was retrieved from the Register of the Total Population (Statistics Sweden), which is continuously updated with all births, deaths, immigration, emigration and migration within Sweden. ${ }^{26}$

Registration records for each academic year (spring and autumn) at university during 1993 through 2011 were obtained from the administrative data for university and higher education (Statistics Sweden). Highest attained level of education was retrieved from the Longitudinal Integration Database for Health Insurance and Labour Market studies (LISA, Statistics Sweden).

Dates and causes of death were retrieved from the Cause of Death Register (CDR, National Board of Health and Welfare), which contains all deaths of residents in Sweden since 1961. ${ }^{27}$ The unique personal identification number assigned to all residents in Sweden was used for accurate linkage of information between the registers. ${ }^{28}$

\section{Classification of exposure}

All participants were checked for registration at university for each year (1993-2011) during spring and autumn semesters-if there was no such record, persontime was categorised according to educational attainment. For each subject throughout the study period, the current person-time was allocated to the corresponding educational category. Hence, subjects could contribute person-time to more than one educational category; figure 1 illustrates person-time allocation and figure 2 depicts six example subjects and their allocated person-time.

We defined ongoing university studies as being registered at university during the spring and/or autumn semester of each year. Since registration is not recorded instantly at the start of a semester, we defined the spring semester as starting from 1 March and continuing to 31 September, including the summer months $(7 / 12$ years $)$, and the autumn semester lasting from 1 October to 28 February (5/12 years person-time) each year. Doctoral education was not included in this category.

For periods without registration at university, persontime was allocated to one of three different categories of non-student exposure, according to highest attained level of education: secondary education or less (9 years of schooling, compulsory in Sweden), upper secondary education (12 years of schooling) and attained university education (tertiary education). The level of attained university education ranged from a minimum of one completed semester at university to finalised postgraduate education.

\section{Outcomes}

The main outcome was suicide, recorded in the CDR as underlying cause of death according to the International Statistical Classification of Diseases and Related Health Problems (ICD, versions 9 and 10) as suicide (ICD-9: E950-E959, ICD-10: X60-X84) or as death with undetermined intent (ICD-9: E980-E989, ICD-10: Y10-Y34). Secondary outcomes were unnatural
Figure 1 Flow chart over allocation of person-time under exposure conditions.

\section{Exposure conditions}

Every 18-39 year old in Sweden was checked for registration at university (AUH) for each year during 1993 through 2011 at spring and autumn semesters -

if not, person-time was categorised according to educational attainment (LISA)

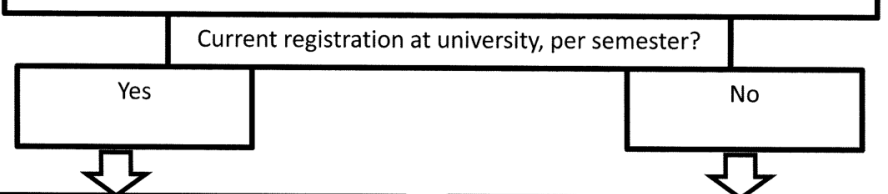

Person-years as non-student according to educational attainment

Person-years as university student $\leq 9$ years schooling attained

12 years schooling attained

university, minimum 1 semester attained (ref) 


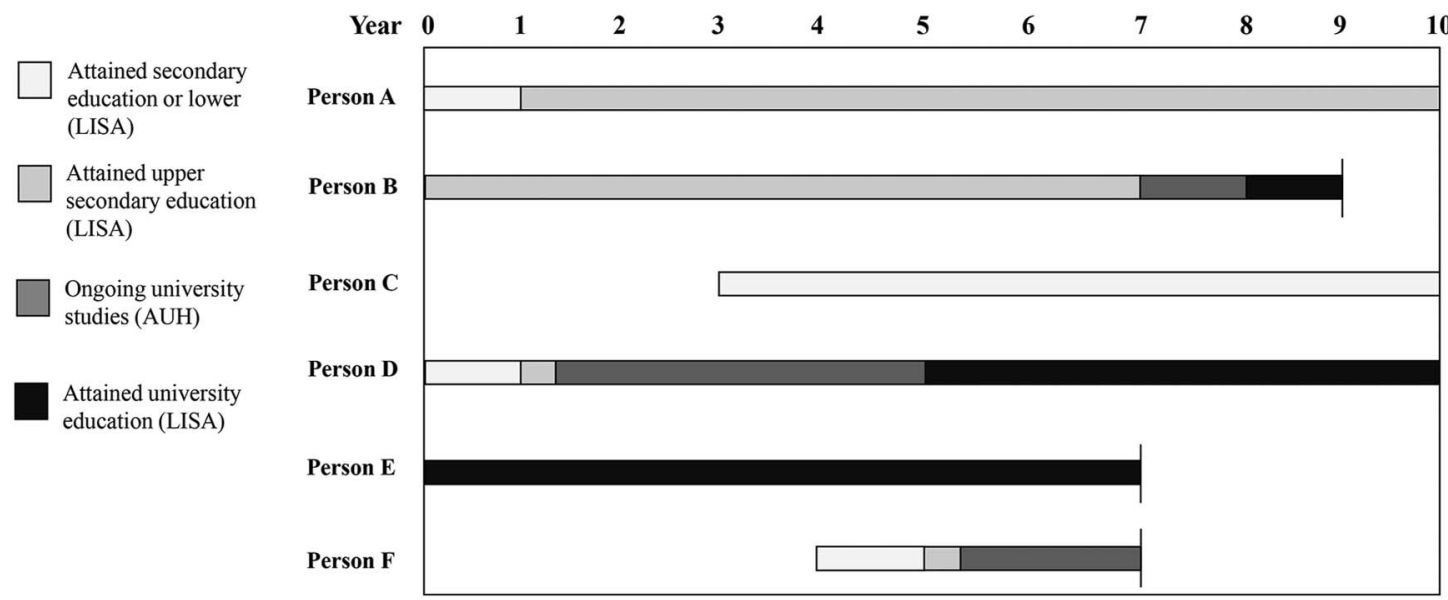

Figure 2 An illustration of how exposure was measured according to educational status. The figure shows how person-time under the exposure educational status was assigned for six example persons (A-F) during a period of 10 years. If not currently studying at university, person-time for each subject was allocated to the exposure of highest attained education. Person $(A)$ is included in year 0 at age 18; attains upper secondary education after 1 year and does not pursue university studies. Person (B) is included in year 0 at age 20; has attained upper secondary education; studies at university year 7-8 and dies at year 9. Person (C) is included at year 3 when he reaches age 18; has attained secondary education and does not pursue further studies. Person (D) is included at year 0 at age 18; attains upper secondary education after 1 year; starts at university in August but is registered for the autumn semester in September, thus during year 2 has exposure of attained 12 years for 3 months and then pursues studies at university for 3 years and attained university education from year 5 and on. Person (E) is included at year 0 at 33 years; has attained university studies and is censored year 7 when reaching age 40 . Person (F) is included at year 4 at 18 years; has attained upper secondary education after 1 year; starts university at year 5 ; is registered after 3 months during which she has the exposure attained 12 years; moves abroad at year 7 and is censored. AUH, administrative data for university and higher education; LISA, Longitudinal integration database for health insurance and labour market studies.

death (ICD-9: E800-E999 and ICD-10: V01-Y99, including suicide as above) and all-cause death. ${ }^{29}$

\section{Statistical analysis}

Poisson regression analyses were used to examine the association between educational category and suicide by calculating the incidence rate ratio (IRR) with a $95 \%$ CI. We assessed person-time by adding the time the subjects were alive and living in Sweden under each of the exposure conditions. Attained university education was chosen as reference. Three regression models stratified by sex were analysed; Model I crude, Model II adjusted for age in three categories (18-24, 25-29 and 30-39 years) and Model III (presented in text only), additionally adjusted for period (1993-1999, 2000-2005 and 2006-2011). To avoid bias from the inclusion of deaths with undetermined intent to the suicide outcome, we performed a sensitivity analysis where deaths with undetermined intent were excluded. Second, in order to investigate any confounding effect of country of birth, we performed another sensitivity analysis where we excluded subjects born outside of Scandinavia.

SAS Genmod procedure was used to calculate IRRs and $95 \%$ CIs for suicide and other death. SAS V. 9.4 (SAS Institute, Cary, North Carolina, USA) was used.

\section{RESULTS}

The open cohort included 5039419 individuals, of whom 2569266 (51\%) were men and 2470193 (49\%) were women. We identified a total of 7316 deaths due to suicide (table 1), of which 541 were registered during ongoing university studies. Suicides constituted $63.4 \%$ of all unnatural deaths $(\mathrm{N}=11533)$ and $29.7 \%$ of all deaths ( $\mathrm{N}=24$ 672). During ongoing university studies, suicides constituted $71.4 \%$ of the unnatural deaths $(\mathrm{N}=757)$ and $36.4 \%$ of all deaths $(\mathrm{N}=1485)$.

Rates of suicide and all-cause death were highest for the exposure category with secondary or lower education and lowest for the category with attained university education. Suicide mortality rates for ongoing university studies were 19.0/100 000 person-years for men and 7.2/100 000 person-years for women (table 1 ).

The proportion of person-years in ongoing university studies (as students) was largest for 18-24-year-olds and lowest for 30-39-year-olds for both sexes (tables 2 and 3 ). The proportion of person-years of attained university education was highest for 30-39-year-olds and lowest for 18-24-year-olds. In the age groups 18-24 and 25-29 years, larger proportions of female suicides, 8.6-18\%, than male suicides, $7.2-12.5 \%$, occurred during ongoing university studies over the three periods (tables 2 and 3).

Table 4 presents IRRs for the association between educational status and suicide or all-cause death. In Model II, adjusted for age, the IRRs indicated a higher risk during ongoing university studies compared with when having attained university studies, for men (IRR $=2.37$, $95 \%$ CI 2.07 to 2.72) and for women (IRR=2.15, 95\% CI 1.77 to 2.61$)$. The association was marginally stronger 
Table 1 Mortality rate per 100000 person-years of suicides and all-cause deaths with $95 \%$ Cls by sex and educational status, for individuals aged 18-39 during 1993-2011 in Sweden

\begin{tabular}{|c|c|c|c|c|}
\hline \multirow[b]{3}{*}{ Educational status } & \multicolumn{4}{|c|}{ Mortality } \\
\hline & \multicolumn{2}{|c|}{ Suicide } & \multicolumn{2}{|c|}{ All-cause death } \\
\hline & $\overline{\mathbf{N}}$ & Rate $(95 \% \mathrm{Cl})$ & $\overline{\mathbf{N}}$ & Rate $(95 \% \mathrm{Cl})$ \\
\hline \multicolumn{5}{|l|}{ Men } \\
\hline Secondary or lower & 1746 & 41.0 (39.1 to 42.9$)$ & 5620 & 132.0 (128.6 to 135.5$)$ \\
\hline Upper secondary & 2766 & 22.3 (21.5 to 23.1$)$ & 8761 & $70.6(69.1$ to 72.1$)$ \\
\hline Ongoing university & 358 & 19.0 (17.0 to 21.0$)$ & 907 & 48.2 (45.0 to 51.3 ) \\
\hline Attained university & 539 & 10.4 (9.6 to 11.3$)$ & 1813 & 35.1 (33.5 to 36.7 ) \\
\hline \multicolumn{5}{|l|}{ Women } \\
\hline Secondary or lower & 610 & 17.3 (15.9 to 18.7$)$ & 2122 & 60.1 (57.6 to 62.7$)$ \\
\hline Upper secondary & 858 & 7.8 (7.3 to 8.3$)$ & 3560 & 32.5 (31.4 to 33.5$)$ \\
\hline Ongoing university & 183 & $7.2(6.2$ to 8.3$)$ & 578 & 22.8 (21.0 to 24.7 ) \\
\hline Attained university & 256 & 4.3 (3.8 to 4.9$)$ & 1311 & 22.2 (21.0 to 23.4$)$ \\
\hline
\end{tabular}

when additional adjustment for period was made (Model III, not shown in table). A sensitivity analysis, excluding verdicts of undetermined intent from the suicide outcome, did not considerably change the estimates.

The IRR for all-cause mortality, adjusted for age (Model II), also indicated a higher risk during ongoing university studies compared with after having attained at least one semester of university education. For men, IRR was 1.88 (95\% CI 1.73 to 2.04) and for women 1.55 (95\% CI 1.40 to 1.71 ).

For unnatural death, the IRR indicated an approximately twofold higher risk during ongoing university studies compared with when having attained university education for men (IRR=2.02, 95\% CI 1.80 to 2.27 ) and for women (IRR $=1.96,95 \%$ CI 1.67 to 2.30 ) (not shown in table). A sensitivity analysis revealed similar associations for all three outcomes for individuals born within and outside of Scandinavia.

\section{DISCUSSION}

In this nationwide cohort study, attending university studies was associated with a twofold risk of suicide compared with not being a student but having attained a university education. The risk was slightly higher for men than for women.

The population cohort, using large national registers of high quality and validity with complete nationwide coverage of exposure (ongoing university studies and educational attainment) as well as outcome (suicide and other death) and a long observation time, is unprecedented in university student suicide research and provides the present study with high generalisability, negligible bias due to selection or loss to follow-up, as well as considerable power.

To the best of our knowledge, this is the first study of university student suicide that takes educational attainment in non-students into account. Results from previous studies may have been confounded due to differences in educational level. Low educational attainment is associated with a higher risk for all-cause death and suicide. ${ }^{16-19}$ High educational attainment is associated with a better overall health and a lower mortality. ${ }^{19}$ However, a higher educational level is associated with a higher risk of suicide rather than other causes of death compared with those with a lower educational level. ${ }^{30}$

Swedish suicide mortality statistics have proven to have a high level of accuracy when analysed for reliability. ${ }^{31}$ Still, in order to avoid any underestimation of the number of suicides in our cohort, we included death with undetermined intent, which is in line with several previous studies. ${ }^{32}{ }^{33}$ Retrospective analyses of deaths of undetermined intent suggest that these should be included in the definition of suicide ${ }^{34}$ and all deaths in Sweden due to suicide or undetermined intent are examined by forensic medicine. To investigate whether suicide risk estimates were biased, we conducted sensitivity analyses, excluding death by undetermined intent, which did not substantially affect estimates.

The generalisability of our results may be affected by the fact that education in Sweden is tuition free and that all university students are granted general financial aid during ongoing studies. In contrast to many other countries, this allows for anyone with sufficient motivation, grades and previous educational attainment to enter higher education. This is a longitudinal study of an entire national student population and therefore our results contribute with a higher representativeness than any previous study.

A recent study of university student suicides among mental health patients in the UK found 214 deaths by suicide in the studied time period and no clear predominance for male suicides. ${ }^{35}$ In the present study, we found a higher IRR for male suicides among university students, yet the gap between men and women was smaller for students compared with non-students who had attained upper secondary education. Further, there was a tendency towards a larger proportion of 
Table 2 Men's suicides and distribution of person-years by age, period and educational status in Sweden

\begin{tabular}{|c|c|c|c|c|c|c|c|c|c|c|c|c|c|}
\hline \multirow[b]{2}{*}{ Age } & \multirow[b]{2}{*}{ Educational status } & \multicolumn{4}{|c|}{ 1993-1999 } & \multicolumn{4}{|c|}{ 2000-2005 } & \multicolumn{4}{|c|}{ 2006-2011 } \\
\hline & & $\begin{array}{l}\text { No. } \\
\text { suic }\end{array}$ & Per cent & $\begin{array}{l}1000 \\
\text { Pyrs }\end{array}$ & Per cent & $\begin{array}{l}\text { No. } \\
\text { suic }\end{array}$ & Per cent & $\begin{array}{l}1000 \\
\text { Pyrs }\end{array}$ & Per cent & $\begin{array}{l}\text { No. } \\
\text { suic }\end{array}$ & Per cent & $\begin{array}{l}1000 \\
\text { Pyrs }\end{array}$ & Per cent \\
\hline \multirow[t]{4}{*}{$18-24$} & Secondary or lower & 143 & (39.0) & 637 & $(25.6)$ & 212 & $(51.2)$ & 631 & (29.3) & 252 & $(46.5)$ & 715 & (28.6) \\
\hline & Upper secondary & 181 & (49.3) & 1375 & (55.2) & 165 & $(40.0)$ & 1093 & $(50.7)$ & 212 & (39.1) & 1295 & (51.8) \\
\hline & Ongoing university & 42 & (11.4) & 343 & (13.8) & 37 & (8.9) & 346 & $(16.0)$ & 68 & (12.5) & 380 & (15.2) \\
\hline & Attained university & 1 & $(0.3)$ & 135 & $(5.4)$ & 6 & (1.4) & 87 & $(4.0)$ & 10 & $(1.8)$ & 113 & $(4.5)$ \\
\hline \multirow[t]{4}{*}{$25-29$} & Secondary or lower & 131 & (31.7) & 284 & $(14.2)$ & 107 & (31.8) & 181 & (10.9) & 170 & $(35.0)$ & 218 & (13.2) \\
\hline & Upper secondary & 221 & (53.4) & 1119 & (56.2) & 171 & (50.9) & 870 & (52.4) & 224 & $(46.1)$ & 779 & $(47.1)$ \\
\hline & Ongoing university & 30 & $(7.2)$ & 162 & $(8.2)$ & 32 & $(9.5)$ & 173 & $(10.4)$ & 52 & (10.7) & 174 & (10.5) \\
\hline & Attained university & 32 & $(7.7)$ & 427 & (21.4) & 26 & $(7.7)$ & 438 & (26.4) & 40 & $(8.2)$ & 484 & $(29.2)$ \\
\hline \multirow[t]{4}{*}{ 30-39 } & Secondary or lower & 329 & $(30.0)$ & 754 & (19.0) & 210 & $(24.4)$ & 453 & (12.1) & 192 & $(21.8)$ & 385 & (10.9) \\
\hline & Upper secondary & 607 & (55.1) & 2077 & (52.4) & 495 & (57.6) & 2047 & (54.4) & 490 & (55.6) & 1751 & (49.6) \\
\hline & Ongoing university & 32 & $(2.9)^{\prime}$ & 94 & $(2.4)$ & 23 & $(2.7)$ & 111 & $(2.9)^{\prime}$ & 42 & $(4.8)$ & 100 & $(2.8)$ \\
\hline & Attained university & 134 & (12.2) & 1039 & $(26.2)$ & 132 & (15.3) & 1150 & (30.6) & 158 & (17.9) & 1296 & (36.7) \\
\hline
\end{tabular}

No, number of; Pyrs, person-years; Suic, suicides.

Table 3 Women's suicides and distribution of person-years by age, period and educational status in Sweden

\begin{tabular}{|c|c|c|c|c|c|c|c|c|c|c|c|c|c|}
\hline \multirow[b]{2}{*}{ Age } & \multirow[b]{2}{*}{ Educational status } & \multicolumn{4}{|c|}{ 1993-1999 } & \multicolumn{4}{|c|}{ 2000-2005 } & \multicolumn{4}{|c|}{ 2006-2011 } \\
\hline & & $\begin{array}{l}\text { No. } \\
\text { suic }\end{array}$ & Per cent & $\begin{array}{l}1000 \\
\text { Pyrs }\end{array}$ & Per cent & $\begin{array}{l}\text { No. } \\
\text { suic }\end{array}$ & Per cent & $\begin{array}{l}1000 \\
\text { Pyrs }\end{array}$ & Per cent & $\begin{array}{l}\text { No. } \\
\text { suic }\end{array}$ & Per cent & $\begin{array}{l}1000 \\
\text { Pyrs }\end{array}$ & Per cent \\
\hline \multirow[t]{4}{*}{$18-24$} & Secondary or lower & 64 & $(45.0)$ & 597 & (24.4) & 82 & (59.0) & 538 & $(26.2)$ & 93 & $(47.0)$ & 608 & $(25.5)$ \\
\hline & Upper secondary & 59 & $(41.5)$ & 1272 & (52.1) & 44 & (31.6) & 951 & (46.2) & 74 & $(37.4)$ & 1118 & $(47.0)$ \\
\hline & Ongoing university & 18 & (12.7) & 423 & (17.3) & 12 & (8.6) & 438 & (21.3) & 28 & $(14.1)$ & 497 & (20.9) \\
\hline & Attained university & 1 & $(0.7)$ & 152 & $(6.2)$ & 1 & $(7.2)$ & 130 & (6.3) & 3 & $(1.5)$ & 157 & $(6.6)$ \\
\hline \multirow[t]{4}{*}{$25-29$} & Secondary or lower & 45 & (34.6) & 255 & (13.0) & 33 & $(27.0)$ & 142 & (8.9) & 38 & $(27.1)$ & 153 & $(9.7)$ \\
\hline & Upper secondary & 54 & (41.5) & 1066 & (54.5) & 56 & (45.9) & 708 & (44.4) & 57 & $(40.7)$ & 583 & $(37.1)$ \\
\hline & Ongoing university & 14 & $(10.8)$ & 169 & (8.6) & 22 & (18.0) & 210 & (13.2) & 21 & (15.0) & 218 & (13.9) \\
\hline & Attained university & 17 & (13.1) & 466 & (23.8) & 11 & $(9.0)$ & 534 & (33.5) & 24 & (17.1) & 618 & (39.3) \\
\hline \multirow[t]{4}{*}{ 30-39 } & Secondary or lower & 98 & (26.3) & 599 & (15.4) & 79 & (24.7) & 345 & $(9.5)$ & 78 & (22.7) & 292 & $(8.6)$ \\
\hline & Upper secondary & 204 & (54.8) & 2043 & (52.4) & 162 & (50.6) & 1828 & (50.5) & 148 & (43.0) & 1395 & (40.9) \\
\hline & Ongoing university & 22 & $(5.9)$ & 161 & $(4.1)$ & 16 & $(5.0)$ & 222 & $(6.1)$ & 30 & $(8.7)$ & 195 & $(5.7)$ \\
\hline & Attained university & 48 & (12.9) & 1099 & (28.2) & 63 & (19.7) & 1223 & (33.8) & 88 & (25.6) & 1532 & (44.9) \\
\hline
\end{tabular}


Table 4 Incidence rate ratio of suicide and all-cause death by educational status, with $95 \% \mathrm{Cls}$ for men and women aged 18-39, residents in Sweden, between 1993 and 2011

\begin{tabular}{|c|c|c|c|c|}
\hline \multirow[b]{2}{*}{ Educational status } & \multicolumn{2}{|l|}{ Suicide } & \multicolumn{2}{|l|}{ All-cause death } \\
\hline & Model I & Model II* & Model I & Model II* \\
\hline \multicolumn{5}{|l|}{ Men } \\
\hline Secondary or lower & 3.93 (3.57 to 4.33$)$ & $4.76(4.31$ to 5.25$)$ & 3.76 (3.57 to 3.97$)$ & 4.66 (4.41 to 4.91$)$ \\
\hline Upper secondary & 2.14 (1.95 to 2.34$)$ & 2.39 (2.18 to 2.62$)$ & 2.01 (1.91 to 2.12$)$ & 2.28 (2.17 to 2.40$)$ \\
\hline Ongoing university & $1.82(1.60$ to 2.08$)$ & 2.37 (2.07 to 2.72$)$ & 1.37 (1.27 to 1.49$)$ & 1.88 (1.73 to 2.04$)$ \\
\hline Attained university & 1 & 1 & 1 & 1 \\
\hline \multicolumn{5}{|l|}{ Women } \\
\hline Secondary or lower & 3.99 (3.45 to 4.62$)$ & 4.90 (4.22 to 5.69$)$ & 2.71 (2.53 to 2.90$)$ & 3.67 (3.42 to 3.94 ) \\
\hline Upper secondary & 1.81 (1.57 to 2.08$)$ & 2.01 (1.75 to 2.32 ) & $1.46(1.37$ to 1.56$)$ & 1.71 (1.61 to 1.83$)$ \\
\hline Ongoing university & 1.67 (1.38 to 2.02$)$ & 2.15 (1.77 to 2.61$)$ & $1.03(0.93$ to 1.13$)$ & 1.55 (1.40 to 1.71$)$ \\
\hline Attained university & 1 & 1 & 1 & 1 \\
\hline
\end{tabular}

Attained university education is reference category.

${ }^{*}$ Adjusted for age (18-24), (25-29) and (30-39).

female suicides occurring during ongoing university education.

The university student suicide rates found in the current study are higher than those reported in American studies of college and university students. ${ }^{20-25}$ We found a suicide rate for ongoing studies of 19.0/ 100000 person-years for men, considerably higher than the suicide rate of 10.9/100 000 person-years for men in a study of 645 university and college campuses. ${ }^{20}$ Similarily, the suicide rate for women in the present study was higher, 7.2/100 000 person-years, compared with $3.1 / 100000$ person-years. $^{20}$ Another study of suicide rates at 12 American university campuses found a rate of 10.0/100 000 person-years for men and $4.5 / 100000$ person-years for women. ${ }^{21}$ A comparison of US university and college student suicide rates over four eras from 1920-2004 found that the rate of suicide decreased over time from 13.4 in the first period to 6.5 in the most recent. ${ }^{22}$ One explanation for the differences in suicide rates may be that the educational systems are different in Sweden compared with the USA. Although exposure to the first university years in Sweden may be considered similar to US college education, Swedish higher education, being tuition free, may be considered more easily accessible. This may allow for a more heterogeneous student population in Sweden, with a larger proportion of vulnerable individuals. Further possible explanations to the differences in suicide rates may be that data from the national Swedish registers are more comprehensive and provide more accurate estimates. Previous studies have had concerns with possible under-reporting of suicides from universities. ${ }^{26}$

By comparing suicide risk during ongoing university studies with the risk according to attained level of education, our study provides a further differentiated picture of student suicide risk than previous studies. In a study of Oxford university students, a slightly higher suicide rate than expected was found among 18-25-year-olds in England and Wales. ${ }^{23}$ However, two other British studies showed no difference in suicide rates between students at high-ranking Oxford University and Cambridge University and suicide rates in the general population of the same age. ${ }^{24} 25$

As a considerable number of university students are older than 18-24 years, we extended the age span of persons in the cohort up to 39 years. Most students with ongoing university studies are between 18 and 24 years and thus this age span contributed more to the main exposure, whereas most that had attained university were 30-39 years old and therefore contributed with more person-years to this reference category. This may explain why our estimates changed considerably when adjusting for age. Further, students over 25 years have been found to have a significantly higher suicide risk than younger students. ${ }^{21}$

Some limitations should be mentioned. Although a nationwide study, our results may not be generalisable to students in countries whose educational systems differ substantially from the Swedish. It may, furthermore, be argued that those who have attained university education are a selected population that was never at risk of suicide during ongoing studies. However, the category of attained university education in the present study was considerably heterogeneous, including persons with only one completed semester as well as persons with a degree or even a doctoral education. Further, as individuals could move between exposure conditions, we argue that such an objection is weakened.

Most importantly, we have not investigated possible explanations for the higher suicide risk during ongoing university studies. These are most likely multifactorial and complex. The university or college environment presents demands and expectations of achievement which may cause considerable mental distress in some individuals. ${ }^{4-7} \mathrm{~A}$ recent study suggests that first-onset suicidal behaviour and thoughts are more common in university students than in a general population sample. ${ }^{36}$ Depression, which is a risk factor for suicide, has been found to be more common among university students than in the general population. ${ }^{4} 59$ In a study of 
patients admitted to a psychiatric hospital after attempted suicide, university students were younger, used less violent methods and were less likely to have a history of substance abuse compared with other patients. $^{37}$

Future studies should investigate which specific risk factors, for example, mental distress, performancerelated anxiety, type of education and university, are associated with suicide risk in university students.

\section{CONCLUSION}

In conclusion, this national cohort study shows a twofold higher risk of death by suicide during ongoing university studies compared with during time as non-student with some prior terminated university education. University students who take their lives die from a preventable cause and despite being protected by known factors that decrease suicide risk such as having a high educational attainment. Our findings demonstrate the need of attention from public health efforts and student healthcare.

\section{Author affiliations}

${ }^{1}$ Department of Clinical Neuroscience, Centre for Psychiatry Research, Karolinska Institutet \& Stockholm Health Care Services, Stockholm County Council, Stockholm, Sweden

${ }^{2}$ Institute of Environmental Medicine, Karolinska Institutet, Stockholm, Sweden

${ }^{3}$ Department of Clinical Neuroscience, Division of Insurance Medicine, Karolinska Institutet, Stockholm, Sweden

Contributors MD had the original idea for the study and designed it together with $\mathrm{RL}$ and MV. The authors are grateful to Professor Bo Runeson for his contribution in discussions of study design and results. MD and MV managed the data set and Fredrik Mattson at FM Statistikkonsult has contributed with statistical analyses. CTL, MD, RL and MV interpreted results and cowrote the paper. MD is guarantor.

Funding This work was supported by Forte, Swedish Research Council for Health, Working Life and Welfare (grant number: 2015-00656), The Swedish Society of Medicine (grant number: SLS-409611) and Söderström-Königska Foundation (grant number: SLS-383851).

\section{Competing interests None declared.}

Ethics approval This study was approved by the Regional Ethical Review Board in Stockholm (diary number 2012-1669-31/5).

Provenance and peer review Not commissioned; externally peer reviewed.

Data sharing statement No additional data are available.

Open Access This is an Open Access article distributed in accordance with the Creative Commons Attribution Non Commercial (CC BY-NC 4.0) license, which permits others to distribute, remix, adapt, build upon this work noncommercially, and license their derivative works on different terms, provided the original work is properly cited and the use is non-commercial. See: http:// creativecommons.org/licenses/by-nc/4.0/

\section{REFERENCES}

1. Saxena S, Krug EG, Chestnov O. Organisation mondiale de la santé. Preventing suicide: a global imperative. Geneva: World Health Organisation, 2014

2. OECD (2014), Education at a glance 2014: OECD indicators, OECD Publishing. (accessed 18 Jun 2016).

3. Statistiska centralbyrån. Var fjärde i Sverige är högutbildad (Translation: every fourth Swede has attained university education). Befolkningens utbildning 2014, 2015. http://www.sverigeisiffror.scb. se/hitta-statistik/sverige-i-siffror/utbildning-jobb-och-pengar/ befolkningens-utbildning/ (accessed 18 Aug 2016).

4. Dahlin M, Joneborg N, Runeson B. Stress and depression among medical students: a cross-sectional study. Med Educ 2005;39:594-604

5. Ibrahim AK, Kelly SJ, Adams CE, et al. A systematic review of studies of depression prevalence in university students. J Psychiatr Res 2013;47:391-400.

6. Blanco C, Okuda M, Wright C, et al. Mental health of college students and their non-college-attending peers results from the National Epidemiologic Study on Alcohol and Related Conditions. Arch Gen Psychiatry 2008;65:1429-37.

7. Delara M, Woodgate RL. Psychological distress and its correlates among university students: a cross-sectional study. J Pediatr Adolesc Gynecol 2015;28:240-4.

8. Vaez M, Ponce de Leon A, Laflamme L. Health-related determinants of perceived quality of life: a comparison between first-year university students and their working peers. Work 2006;26:167-77.

9. Stallman HM. Psychological distress in university students: a comparison with general population data. Australian Psychologist 2010;45:249-57.

10. Vaez M, Kristenson M, Laflamme L. Perceived quality of life and self-rated health among first-year university students-a comparison with their working peers. Social Indicators Research 2004;68:221-34.

11. Brazeau CM, Shanafelt T, Durning SJ, et al. Distress among matriculating medical students relative to the general population. Acad Med 2014;89:1520-5.

12. Garlow SJ, Rosenberg J, Moore JD, et al. Depression, desperation, and suicidal ideation in college students: results from the American Foundation for Suicide Prevention College Screening Project at Emory University. Depress Anxiety 2008;25:482-8.

13. Cukrowicz KC, Schlegel EF, Smith PN, et al. Suicide ideation among college students evidencing subclinical depression. J Am Coll Health 2011;59:575-81.

14. $\mathrm{Li} \mathrm{ZZ}$, Li YM, Lei XY, et al. Prevalence of suicidal ideation in Chinese college students: a meta-analysis. PLOS ONE 2014;9: e104368.

15. Kimura $\mathrm{T}$, Iso $\mathrm{H}$, Honjo $\mathrm{K}$, et al. Educational levels and risk of suicide in Japan: The Japan Public Health Center Study (JPHC) Cohort I. J Epidemiol2016;26:315-21.

16. Shah A, Bhandarkar $R$. The relationship between general population suicide rates and educational attainment: a cross-national study. Suicide Life Threat Behav 2009;39:463-70.

17. Abel EL, Kruger ML. Educational attainment and suicide rates in the United States. Psychol Rep 2005;97:25-8.

18. Bjorkenstam C, Weitoft GR, Hjern A, et al. School grades, parental education and suicide--a national register-based cohort study. J Epidemiol Community Health 2011;65:993-8.

19. Cohen AK, Syme SL. Education: a missed opportunity for public health intervention. Am J Public Health 2013;103:997-1001.

20. Schwartz AJ. Rate, relative risk, and method of suicide by students at 4-year colleges and universities in the United States, 2004-2005 through 2008-2009. Suicide Life Threat Behav 2011;41:353-71.

21. Silverman MM, Meyer PM, Sloane F, et al. The Big Ten Student Suicide Study: a 10-year study of suicides on Midwestern university campuses. Suicide Life Threat Behav 1997;27:285-303.

22. Schwartz AJ. Four eras of study of college student suicide in the United States: 1920-2004. J Am Coll Health 2006;54:353-66.

23. Hawton K, Haigh R, Simkin S, et al. Attempted suicide in Oxford University students, 1976-1990. Psychol Med 1995;25:179-88.

24. Collins IP, Paykel ES. Suicide amongst Cambridge University students 1970-1996. Soc Psychiatry Psychiatr Epidemiol 2000;35:128-32.

25. Hawton $\mathrm{K}$, Bergen $\mathrm{H}$, Mahadevan $\mathrm{S}$, et al. Suicide and deliberate self-harm in Oxford University students over a 30-year period. Soc Psychiatry Psychiatr Epidemiol 2012;47:43-51.

26. Ludvigsson JF, Almqvist C, Bonamy AK, et al. Registers of the Swedish total population and their use in medical research. Eur J Epidemiol 2016;31:125-36.

27. National Board of Health and Welfare in Sweden. Cause of Death Register. National Board of welfare website. http://www. socialstyrelsen.se/register/dodsorsaksregistret (accessed 13 Apr 2016).

28. Ludvigsson JF, Otterblad-Olausson P, Pettersson BU, et al. The Swedish personal identity number: possibilities and pitfalls in healthcare and medical research. Eur J Epidemiol 2009;24:659-67.

29. Anderson RN, Minino AM, Hoyert DL, et al. Comparability of cause of death between ICD-9 and ICD-10: preliminary estimates. Natl Vital Stat Rep 2001;49:1-32. 
30. Pompili M, Vichi M, Qin $\mathrm{P}$, et al. Does the level of education influence completed suicide? A nationwide register study. J Affect Disord 2013;147:437-40.

31. Neeleman J, Wessely S. Changes in classification of suicide in England and Wales: time trends and associations with coroners' professional backgrounds. Psychol Med 1997;27:467-72.

32. Runeson B, Haglund A, Lichtenstein $P$, et al. Suicide risk after nonfatal self-harm: a national cohort study, 2000-2008. J Clin Psychiatry 2016;77:240-6.

33. Tidemalm D, Beckman K, Dahlin M, et al. Age-specific suicide mortality following non-fatal self-harm: national cohort study in Sweden. Psychol Med 2015;45:1699-707.
34. Linsley KR, Schapira K, Kelly TP. Open verdict v. suicideimportance to research. Br J Psychiatry 2001;178:465-8.

35. Farrell S, Kapur N, While D, et al. Suicide in a National Student Mental Health Patient Population, 1997-2012. Crisis 2016:1-7.

36. Mortier P, Demyttenaere K, Auerbach RP, et al. First onset of suicidal thoughts and behaviours in college. J Affect Disord 2017:207:291-9.

37. Rahme E, Low NC, Lamarre S, et al. Attempted suicide among students and young adults in Montreal, Quebec, Canada: a retrospective cross-sectional study of hospitalized and nonhospitalized suicide attempts based on chart review. Prim Care Companion CNS Disord 2015;17. 